\title{
Exchange Flow Variability between Hypersaline Shark Bay and the Ocean
}

\author{
Yasha Hetzel ${ }^{1, *}$, Charitha Pattiaratchi ${ }^{1}$ and Hrvoje Mihanović ${ }^{1,2}$ \\ 1 Oceans Graduate School \& the UWA Oceans Institute, The University of Western Australia, \\ Crawley 6009, Australia; chari.pattiaratchi@uwa.edu.au (C.P.); hrvoje.mihanovic@izor.hr (H.M.) \\ 2 Physical Oceanography Laboratory, Institute of Oceanography and Fisheries, 21000 Split, Croatia \\ * Correspondence: Yasha.hetzel@uwa.edu.au; Tel.: +61-8-6488-8109
}

Received: 22 May 2018; Accepted: 29 May 2018; Published: 1 June 2018

\begin{abstract}
In Shark Bay, a large hypersaline bay in Western Australia, longitudinal density gradients force gravitational circulation that is important for Bay-ocean exchange. First-time observations of vertical stratification and velocity are presented, confirming the presence of a steady, near-bed dense water outflow from Shark Bay's northern Geographe Channel that persisted through all stages of the tide. Outflow velocities were 2-3 times stronger than the outflows recorded previously in Naturaliste Channel (in the west), and were more resistant to breakdown by tidal mixing. Estimates of turbulent kinetic energy production derived from the variance method showed a more complex structure in the Geographe Channel, due to shear between surface and bottom layers. Turbulence varied between flood and ebb tide, with peak levels of turbulence occurring during reversal of tidal flows. For both channels, the main source of turbulence was tidal flow along the seabed, with the bottom current speed cubed, $\left|\mathrm{U}_{\mathrm{b}}{ }^{3}\right|$, providing a reasonable proxy for tidal mixing and prediction of dense water outflows from Shark Bay majority of the time. Orientation and deeper water of the Geographe Channel along the main axis of the longitudinal density gradient provided an explanation for the predominant outflow from the Bay's northern entrance. These density-driven currents could potentially influence recruitment of commercially fished scallops and prawns through the dispersal and flushing of larvae.
\end{abstract}

Keywords: hypersaline bay; circulation; turbulent mixing; exchange flow; Australia; Shark Bay

\section{Introduction}

Horizontal density gradients in coastal bays and estuaries can drive gravitational circulation that is important for the exchange of water, salt and material between bay and ocean. If the water in the bay is less dense than that of the ocean (hyposaline Bay), as is the case in a 'positive' estuary with significant freshwater input, the lighter, fresher water is transported out of the bay at the surface, and is replaced by oceanic water at depth. In places where evaporation exceeds precipitation, elevated nearshore salinities and/or cooling can cause the water in the bay to become denser than the surrounding ocean water (hypersaline Bay), creating a 'negative' horizontal density gradient. This causes the bay to behave as a negative, or 'inverse' estuary, with outflow of dense saline water along the seabed, and an influx of fresher oceanic water at the surface [1]. Intensification of this buoyancy-driven bottom outflow, defined here as a 'dense water outflow', provides an efficient mechanism for the exchange of water, heat, salt, nutrients, and pollutants between the estuary and the ocean. Inverse estuaries and dense water outflows have been documented around Australia on a variety of scales (e.g., [2-7]), as well as globally (e.g., [8-11]), but have been studied much less than positive freshwater estuaries.

The existence of an outflow of high salinity water from Shark Bay, Australia (Figure 1a) (hereafter the Bay), has been implied for some time [12-16]. However, it was only measured indirectly through 
sea floor sediment analyses [14] and hydrographic measurements [15], until a recent field study [17] described intermittent dense water outflows at Naturaliste Channel (one of two main entrance channels-Figure 1a). The outflows were observed at weekly to fortnightly intervals during the winter, and were modulated by the effects of vertical mixing due to wind and tidal action.

The driving forces for the modulation of the outflow at Naturaliste Channel were explored by looking at the relationships between tidal mixing (using bottom current speed $\left|\mathrm{U}_{\mathrm{b}}{ }^{3}\right|$ as a proxy) and wind mixing (using wind speed cubed $\left|\mathrm{W}^{3}\right|$ as a proxy), similar to the methods of Nunes and Lennon [6]. Turbulent mixing caused by wind and tide has been shown to modulate gravity currents (analogous to the dense water outflows described here) in both the laboratory [18] and the field [4,9]. The data from Naturaliste Channel (Figure 1a) indicated that the outflows occurred when tidal currents, the main source of turbulent mixing, were low. These outflow events occurred at regular intervals, when the mixed tides became mostly diurnal, even when those periods coincided with increased tidal range, due to the increased duration of the flood and ebb [17].

(a)

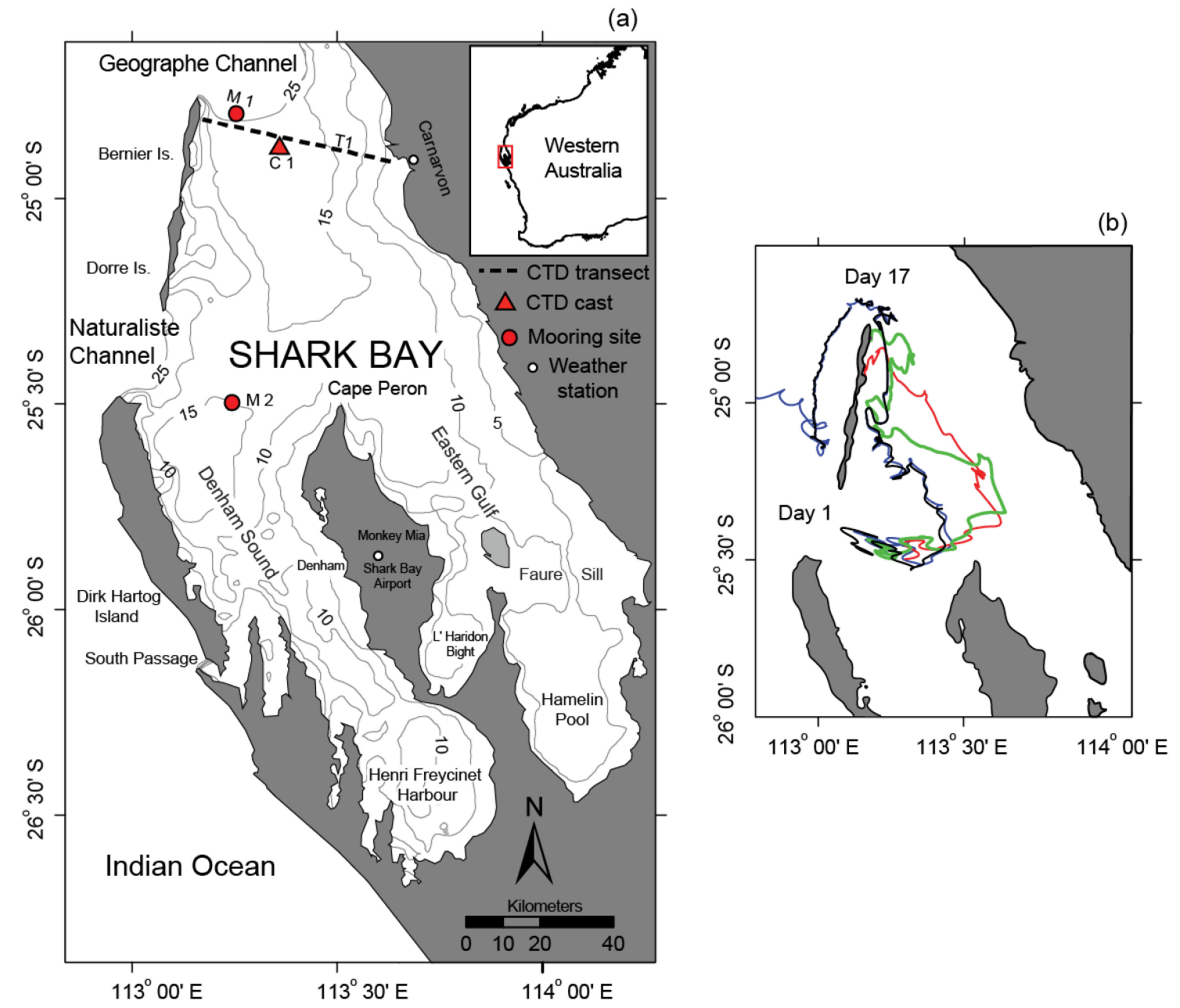

Figure 1. Map of Shark Bay, Western Australia. (a) Map of the study site showing the Conductivity-Temperature-Depth (CTD) transect recorded on 23 August 2011 (T1), the repeated CTD cast location in the deepest part of the Geographe Channel (C1), locations of moorings for the 2011 experiment (M1), and the July 2009 mooring (M2). Depth contours for 5, 10, 15, and $25 \mathrm{~m}$ are shown. Australian Bureau of Meteorology (BOM) weather data used for the analysis were collected at indicated weather stations. (b) Trajectories of four Global Positioning System (GPS) drifters released along a transect in Naturaliste Channel on 25 June 2009. Drifters were designed to follow the surface waters with a subsurface 'holey sock' drogue extending to $2 \mathrm{~m}$ below the surface. 
During the same field experiment, four Global Positioning System (GPS) Lagrangian surface drifters (Figure 1b) were released in the western Naturaliste Channel (not published previously). All drifters exited from the northern entrance of Shark Bay, or were driven ashore near the northern boundary, suggesting a dominant northward surface flow through the northern Geographe Channel; however, the absence of observations at the northern channel restricted further analysis.

Subsequent numerical modeling experiments [19] indicated that outflows through the two main channels responded differently to wind and tidal forcing, with the predominance of outflow passing through the deeper, northern entrance channel, that could persist through all stages of the tide. This contrasted with the observed outflows in the western channel that were more intermittent, with a stronger tidal component. The modeling further supported previous hypotheses of the importance of the northern channel for exchange (e.g., $[16,20]$ ), but the dynamics in Geographe Channel remained unknown, and are the subject of the present work.

The overall objective is therefore to enhance understanding of the relative importance of the two entrances for water exchange and flushing of biological matter (e.g., larvae), with a focus on the northern channel. Specifically, (1) to confirm the existence of the proposed dominant outflow through the northern Geographe Channel (Figure 1a) using first-time observations of velocity and vertical stratification; and (2) to examine the validity of using the cube of bottom current speed $\left(\left|\mathrm{U}_{\mathrm{b}}{ }^{3}\right|\right)$ as a proxy for vertical mixing and regulation of outflows, using calculations of turbulent kinetic energy (TKE) production from Acoustic Doppler Current Profiler (ADCP) data.

The organisation of the paper is as follows. First, the physical setting of the study site is described. In Section 2, an overview of the field experiment is given, including the instrumentation and data analysis methods. Section 3 describes the results, starting with a description of the density structure of Geographe Channel, the stratification, and the current data, before focusing on the relationship between turbulence and persistence of the dense water outflow. Then, a general comparison is made between the outflows and turbulence in the two entrance channels. Section 4 relates the results to other studies of dense water outflows, and briefly proposes biological implications for Shark Bay fisheries. Finally, Section 5 briefly states the main conclusions.

\section{Study Area}

Shark Bay is a large, shallow, hypersaline bay located between $24^{\circ} 30^{\prime}$ and $26^{\circ} 45^{\prime} \mathrm{S}$ along the Indian Ocean coast of Western Australia [16]. The Bay is a protected UNESCO world heritage area for the diverse marine life, vast seagrass beds, and ancient stromatolite 'living fossils' that exist there [21]. It is the largest semi-enclosed water body in Australia, with a north-south length of $\sim 250 \mathrm{~km}$, width $\sim 100 \mathrm{~km}$, an average depth of only $10 \mathrm{~m}$, and a maximum depth of $29 \mathrm{~m} \mathrm{[16].} \mathrm{The} \mathrm{Bay} \mathrm{is} \mathrm{divided} \mathrm{into} \mathrm{an}$ Eastern Gulf and a Western Gulf (Denham Sound) by the Peron Peninsula, and is separated from the warm, low-salinity waters of the southward-flowing Leeuwin Current [15,22,23] by a chain of barrier islands (Figure 1a). Bay-ocean exchange occurs mostly through two main entrance channels [13]: Naturaliste Channel (width $\sim 30 \mathrm{~km}$ ) in the west, and Geographe Channel (width $\sim 40 \mathrm{~km}$ ) in the north (Figure 1a).

The climate is arid, with local annual rainfall $\sim 200 \mathrm{~mm}$ occurring mostly during the passage of winter cold fronts or occasional summer cyclones [16]. Relatively strong southerly winds (mean $\sim 8 \mathrm{~m} \mathrm{~s}^{-1}$ ) blow consistently during spring and summer (October-March), and are weaker (mean $\sim 5 \mathrm{~m} \mathrm{~s}^{-1}$ ) and more variable during autumn and winter (April-September) $[12,15,24]$. The excess of evaporation ( $2000 \mathrm{~mm}$ ) over precipitation $(\sim 200 \mathrm{~mm})$ causes salinity to increase from the ocean to the innermost reaches of Shark Bay, allowing for its classification as an inverse estuary. In Hamelin Pool (Figure 1a), where Faure Sill restricts flow, salinity levels ( 65) throughout the year are nearly twice those of the adjacent ocean, whilst in Henri Freycinet Harbour, salinity levels are more moderate but still high ( 50) [16]. Mixing by winds and tides causes the bay to be mostly vertically homogeneous in the shallow inner regions, with stratification limited to deeper channels [13]. The strongest longitudinal density gradients occur across fronts at the entrances [13] and over shallow sills in the southern portions 
of the two gulfs $[12,16]$. Temperature gradients reverse seasonally across the entrances, with the Bay becoming warmer than shelf waters in the summer, and cooler during the winter [13].

Tides are mixed, with a range of $\sim 1-1.5 \mathrm{~m}$. The Eastern Gulf experiences mainly semidiurnal tides that are magnified due to tidal resonance, whilst the western region experiences mainly diurnal tides [20]. The mainly diurnal character of the tide in the entrance channels means that the semi-monthly variation in water levels relates more to the declination of the moon above the equator than to the phase of the moon. As a result, we refer to 'tropic' and 'equatorial tides' in place of 'spring' and 'neap tides', respectively. Residual tidal currents modeled by Burling et al. [20] identified a gradual northward movement of water $\left(\sim 0.03 \mathrm{~m} \mathrm{~s}^{-1}\right)$ from Naturaliste Channel to Geographe Channel. Maximum (predicted) tidal currents of $\sim 0.5-1 \mathrm{~m} \mathrm{~s}^{-1}$ occur over Faure Sill, near Cape Peron, and the ocean entrances [13]. The seasonal shift in the phase of the semidiurnal and diurnal forcing causes a smaller tidal range and weaker tidal currents in August and February (1-2 months after the solstices), when the semidiurnal and diurnal forcing is out-of-phase. Within these months, the regime transitions back and forth between a predominantly semidiurnal and a predominantly diurnal system over the semi-monthly cycle, with the strength of the tidal currents (and the associated vertical mixing) sometimes controlled more by the duration of the flood/ebb than by the small variability in the tidal range [17].

\section{Materials and Methods}

\subsection{Field Experiments}

\subsubsection{Geographe Channel (23 August-1 September 2011)}

Density profiles were collected on 23 August 2011, along a $35 \mathrm{~km}$ east-west transect across Geographe Channel (T1 in Figure 1a) at the northern end of Shark Bay. The casts were spaced at two-kilometer intervals, and recorded using a YSI Castaway CTD (conductivity-temperature-depth recorder). Profiles were again measured in the deepest section of the channel (C1 in Figure 1) on 1 September 2011. Coincident satellite sea surface temperature (SST) data from the Global $1 \mathrm{~km}$ SST (G1SST) analysis [25] were also obtained for the study period. Wind data from the Bureau of Meteorology (BOM) weather station at Carnarvon Airport (Figure 1a) indicated that wind directions were from the southeast (night) to southwest (day) (from $160-225^{\circ}$ ) over the entire period, and reached maximum intensity during the afternoons due to the sea breeze.

Two side-by-side moorings $\left(24^{\circ} 46.42^{\prime} \mathrm{S}, 113^{\circ} 14.43^{\prime}\right.$ E; M1 in Figure 1a) with a bottom-mounted $600 \mathrm{kHz}$ Teledyne RDI Workhorse ADCP and a thermistor chain were deployed for the 9-day experiment (23 August-1 September 2011). Unfortunately, tampering caused the ADCP frame to turn upside-down after six days, requiring us to discard data from the last three days. The mooring location (4 km east of Bernier Island in $28 \mathrm{~m}$ water depth) was chosen based on numerical model simulations [19] showing the pathway of the dense water outflow through Geographe Channel, and for the shelter from ocean waves provided by Bernier Island. The ADCP sampled continuously in $0.5 \mathrm{~m}$ bins every $1 \mathrm{~s}(1 \mathrm{~Hz})$, using Mode 12 with 4 sub-ping ensemble averages. The ADCP pressure sensor provided sea level data for the first six days, and Carnarvon tide gauge data were used for qualitative interpretation of vertical stratification when ADCP pressure sensor data were not available. Tidal phase was the same at Carnarvon compared to the mooring site, however the amplitude at Carnarvon was $\sim 30 \%$ greater. The thermistor chain was held vertical by a subsurface buoy, and consisted of two Sea Bird Electronics SBE 37 conductivity sensors mounted $2 \mathrm{~m}$ above the seabed and $5 \mathrm{~m}$ below the surface, with three SBE 39 temperature and pressure sensors evenly spaced between. The instruments sampled every $30 \mathrm{~s}$, at heights of approximately $2 \mathrm{~m}, 7 \mathrm{~m}, 12 \mathrm{~m}, 18 \mathrm{~m}$ and $23 \mathrm{~m}$ above the seafloor. All time data are in local time (AWST, UTC $+8 \mathrm{~h}$ ). Observations from Geographe Channel were not published previously. 


\subsubsection{Naturaliste Channel (25 June-23 July 2009)}

Previously published field data [17] were used for comparison between the two entrances. The velocity data were collected in Naturaliste Channel $\left(25^{\circ} 29.978^{\prime} \mathrm{S}, 113^{\circ} 15.070^{\prime} \mathrm{E}\right.$; M2 in Figure 1a) in $16 \mathrm{~m}$ water depth with a bottom-mounted $1200 \mathrm{kHz}$ Teledyne RDI Workhorse ADCP. Velocity profiles in $0.5 \mathrm{~m}$ bins were sampled continuously every $1 \mathrm{~s}(1 \mathrm{~Hz})$, using Mode 12 with 8 sub-ping ensemble averages. Data from another ADCP deployed further offshore were available, but were not used for the comparison as the temporal resolution of the data was coarser and outflows weaker [17]. SBE39 temperature sensors recorded every $2 \mathrm{~min}$ on a thermistor chain at heights of $1 \mathrm{~m}, 4.5 \mathrm{~m}, 7.5 \mathrm{~m}$, and $13.5 \mathrm{~m}$ above the seabed. Four Global Positioning System (GPS) Lagrangian drifters, with 'Holey sock' type drogues (e.g., [26]) extending to $2 \mathrm{~m}$ below the surface, were released at $5 \mathrm{~km}$ intervals along an east-west transect in Naturaliste Channel on 25 June 2009 (Figure 1b). Locations were transmitted via satellite every $\sim 10-20 \mathrm{~min}$ - these data remained unpublished until now. Wind data from the BOM weather station at Shark Bay Airport near Denham (Figure 1a) were used for interpretation of Naturaliste Channel data, with wind speed cubed used as a proxy for wind mixing energy.

\subsection{Data Analysis}

Five-minute averages of temperature were interpolated vertically to $0.2 \mathrm{~m}$ bins while correcting for tilt on the mooring line due to drag. Salinity time series for the surface and bottom were also averaged to 5 -min bins.

Raw $1 \mathrm{~Hz}$ ADCP beam data were converted to geographical coordinates and averaged into 5-min bins. Principal component analysis (e.g., [27]) was performed, and the data were then rotated to the principal axes of current variance $\left(289^{\circ}\right.$ clockwise from north), with negative values representing flow out of the Bay. Sub-tidal currents were investigated by low-pass filtering the ADCP time series using a PL64 filter [28] with a half power period of $38 \mathrm{~h}$.

Knowledge of the turbulent Reynolds stresses helps with understanding the cycle of vertical mixing and the modulation of stratification and dense water outflows. To this end the present study used the 'variance' method, introduced by Lohrmann et al. [29], and detailed by Stacey et al. [30]. This technique uses ADCP data to estimate turbulent Reynolds stresses by differencing velocity variances along opposing beams. The method has been successfully applied in a number of studies to analyse the structure of turbulence in coastal waters [31-33].

A 10-min averaging window (e.g., [32,33]) was used to calculate the mean velocities and Reynolds stresses $\left(u^{\prime} w^{\prime}\right.$ and $\left.v^{\prime} w^{\prime}\right)$, using the variance method as follows:

$$
\overline{u^{\prime} w^{\prime}}=\frac{\operatorname{var}\left(u_{3}\right)-\operatorname{var}\left(u_{4}\right)}{4 \sin \theta \cos \theta} \text { and } \overline{v^{\prime} w^{\prime}}=\frac{\operatorname{var}\left(u_{1}\right)-\operatorname{var}\left(u_{2}\right)}{4 \sin \theta \cos \theta}
$$

where $u_{1}, u_{2}, u_{3}, u_{4}$ represent along beam velocities, the overbars represent temporal means, and the primes represent temporal fluctuations, $\operatorname{var}()$ indicates the variance, and $\theta$ is the angle of the beams with the vertical $\left(20^{\circ}\right.$ for the ADCP used).

The rate of turbulent kinetic energy (TKE) production (P), in $\mathrm{W} \mathrm{m}^{-3}$ was then estimated from the product of the Reynolds stresses and the velocity shear [34]:

$$
P=-\rho\left(\overline{u^{\prime} w^{\prime}} \frac{\partial \bar{u}}{\partial z}+\overline{v^{\prime} w^{\prime}} \frac{\partial \bar{v}}{\partial z}\right)
$$

where, rho $(\rho)$ is the density of water and $z$ is the vertical coordinate. Weak flows can result in the calculation of negative values of TKE production (P), due to instrument noise [35]. Negative estimates of $\mathrm{P}$ were therefore masked for this analysis. Following the literature, $\mathrm{P}$ has been presented in units of $\log _{10}\left(\mathrm{~W} \mathrm{~m}^{-3}\right)$ in the figures.

A detailed explanation of factors influencing the reliability of Reynolds stress estimates can be found in Lu and Lueck [36] and Williams and Simpson [37]. The use of high frequency sampling using Mode 12 has been found to reduce noise in Reynolds stress estimates [38]; however, values 
are more reliable when they are taken close to the seabed, since the beams become further apart, and contamination due to surface waves occurs near the surface [39]. Although the mooring sites in the present study were somewhat protected from prevailing southwesterly swells by the offshore islands, biases due to surface waves were investigated. Reynolds stresses estimated with the variance method (Equation (1)) were compared to estimates where wave biases were removed using the vertical differencing with adaptive filtering (Vertical AF) method [40]. The Vertical AF method involves spatially filtering along beam velocities to remove bias due to surface waves before applying the variance method.

Comparisons between corrected and uncorrected Reynolds stresses generally showed reasonable agreement near the seabed, with increased wave effects usually confined to the top 3-5 $\mathrm{m}$ of the water column. While the Vertical AF method has been shown to improve the accuracy of Reynolds stress estimates, it also degraded the vertical spatial resolution of the data, obscuring much of the spatial structure of turbulence for the Shark Bay data. As one aim of the present study was to compare the temporal variability and structure of turbulence between entrance channels and not exact magnitudes, the unfiltered stress estimates were used instead of the Vertical AF data. Interpretation of the results focused on the near bed turbulence while ignoring high values near the surface, where confidence in the estimates of $\mathrm{P}$ was low. Only general qualitative comparisons were made between winds (using wind speed cubed as a proxy for wind mixing) and turbulence.

\section{Results}

\subsection{Density Structure}

The CTD transect measured during a weak ebb equatorial tide across Geographe Channel at the start of the field experiment on 23 August (Figure 2) showed a warmer, fresher layer of water over a cooler, more saline bottom layer. In depths shallower than 10-15 m (in the east and west), the water was generally well mixed, whilst in the deeper sections the water column it was vertically stratified $\left(\Delta \rho_{\text {(bottom-surface density) }} \sim 1.2 \mathrm{~kg} \mathrm{~m}^{-3}\right)$, with a sharp pycnocline at $10-15 \mathrm{~m}$ depth $(\sim 50 \%$ of water column depth). Surface waters were characterised by temperatures $\sim 22{ }^{\circ} \mathrm{C}$, salinity $\sim 34.8$, density (sigma-t) $\sim 24.1 \mathrm{~kg} \mathrm{~m}^{-3}$ with cooler, more saline bottom waters in the deepest part of the channel having temperature $\sim 20^{\circ} \mathrm{C}$, salinity $\sim 35.7$, sigma-t $\sim 25.3 \mathrm{~kg} \mathrm{~m}^{-3}$. Concurrent satellite SST data (Figure 3) showed the transect was located offshore (to the north) of the semi-circular front, with surface temperatures characteristic of intruding offshore waters. The cooler temperatures near the bottom were similar to the inner bay, with higher salinity values also indicating that the dense bottom waters had originated within the Bay.

Density profiles were recorded with a CTD at the start and end of the experiment in the deepest part of the channel (depth $\sim 30 \mathrm{~m}$; $\mathrm{C} 1$ in Figure 1) (Figure 4e,f). On and before 23 August, winds were strong and tidal forcing was weak (and mostly diurnal), whilst on 1 September, winds were relatively weak and tidal forcing was stronger (and semidiurnal) (Figure 4a,b). Both profiles consisted of two main layers occupying approximately half the water column each with warm, low-salinity water overlaying cooler, more saline bottom water. On 23 August, stronger winds caused the surface layer to be fully-mixed down to $10 \mathrm{~m}$, whilst the weaker tides allowed some vertical stratification in the lower layers (Figure 4e). On 1 September, the reverse was true, with some stratification in the surface layer, and a completely mixed bottom layer due to increased tidal mixing (below $15 \mathrm{~m}$ depth) (Figure 4f).

The CTD profiles indicated that temperature and salinity were both strongly correlated with density stratification. Therefore, temperatures recorded on the thermistor chain (Figure 4c) gave a proxy for density stratification for the complete experiment over the entire water column. Salinity recorded near the surface and bottom confirmed this (Figure 4d). 


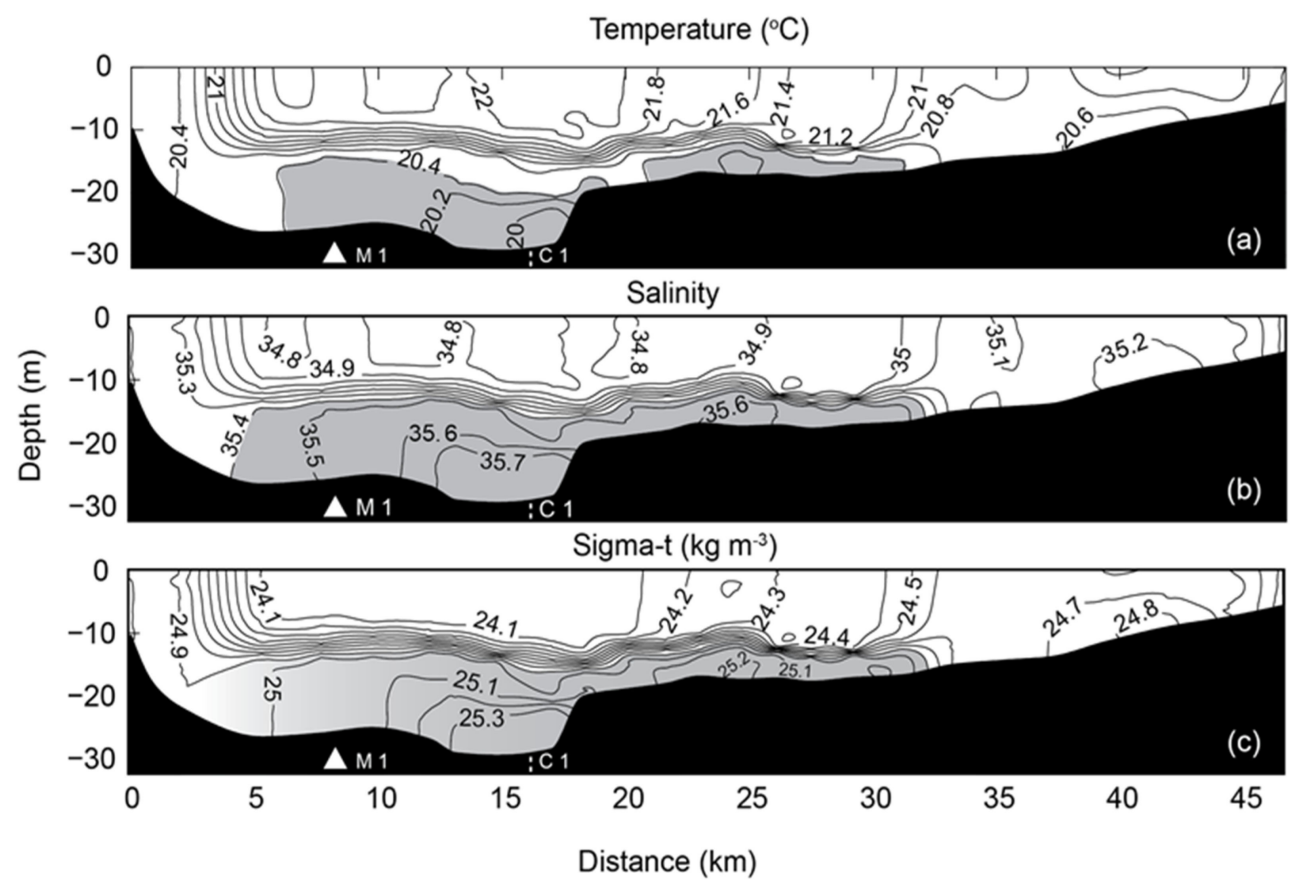

Figure 2. Cross-channel (looking northwards) section of temperature (a), salinity (b), and density (sigma-t) (c) data collected in Geographe Channel on 23 August 2011. Salinity and sigma-t values exceeding mean values are shaded grey and represent Bay waters. The location of mooring M1 is shown with a white triangle, and repeated cast $\mathrm{C} 1$ in the centre of the channel is shown with a dashed line. Distance is along-transect, with origin near the western boundary of the channel.

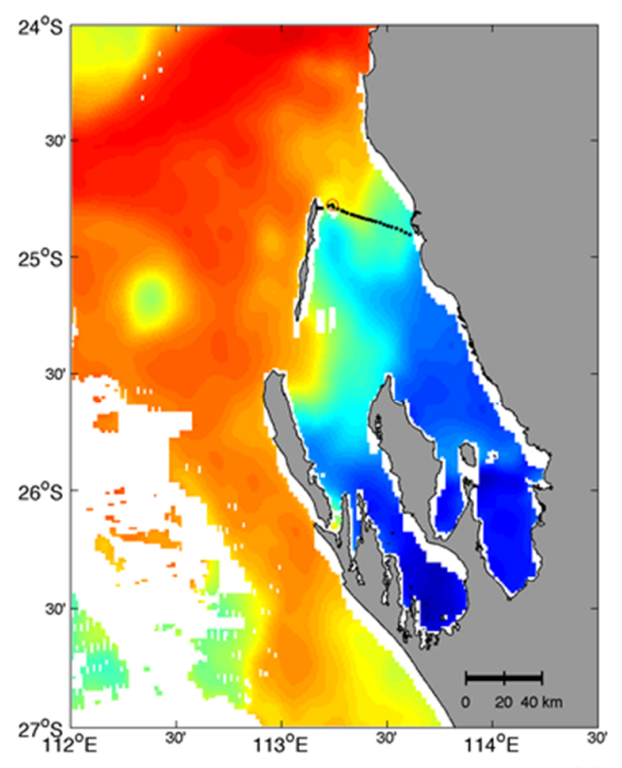

(a)

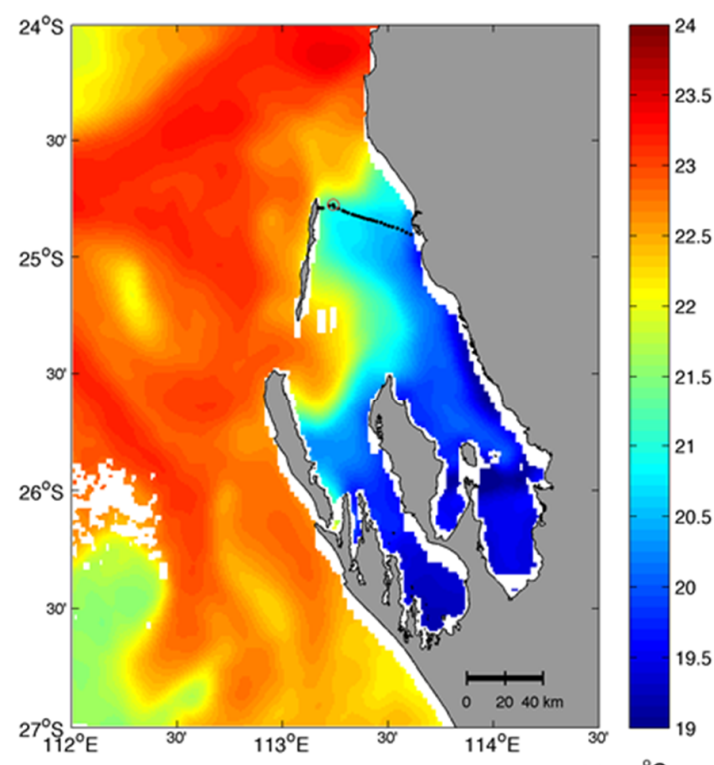

(b) ${ }^{\circ} \mathrm{C}$

Figure 3. Satellite sea surface temperature (SST) data obtained from the G1sst $1 \mathrm{~km}$ dataset for (a) 23 August 2011, and (b) 25 August 2011. The 2011 mooring location (M1) is indicated by a red circle, and the CTD (conductivity-temperature-depth) transect is shown as a black line. The intrusion of the warm Leeuwin Current into the Bay and the location of the front near the mooring is visible, as well as the cooler core of an eddy offshore of Naturaliste Channel. Areas obscured by clouds have been masked and appear white. Note that in (a), the front is to the south of the mooring, and in (b), the front is to the north. 
Vertical density stratification persisted on average over the entire observational period of 9 days (Figure 4c). In the first days, stronger winds mixed the warm surface layer down to within $5 \mathrm{~m}$ of the bottom, whilst during the latter period, the cooler bottom water was mixed upward by stronger tides (Figure $4 \mathrm{a}-\mathrm{c}$ ). Over the entire period, the depth of the pycnocline varied vertically $(\sim 5 \mathrm{~m})$ at tidal frequencies, deepening on the flood tide and lifting on the ebb tide. The magnitude of temperature stratification was strongest $\left(\Delta \mathrm{T}_{\text {surface-bottom }} \sim 1.8^{\circ} \mathrm{C}\right)$ at the beginning of the experiment, but retained a similar structure except during short well-mixed periods (Figure 4c). Salinity stratification was less variable, and reached a maximum towards the end of the experiment $\left(\Delta S_{\text {bottom-surface }}=0.8\right.$ on 30 August, Figure 4d) despite increased tidal forcing (Figure 4b).
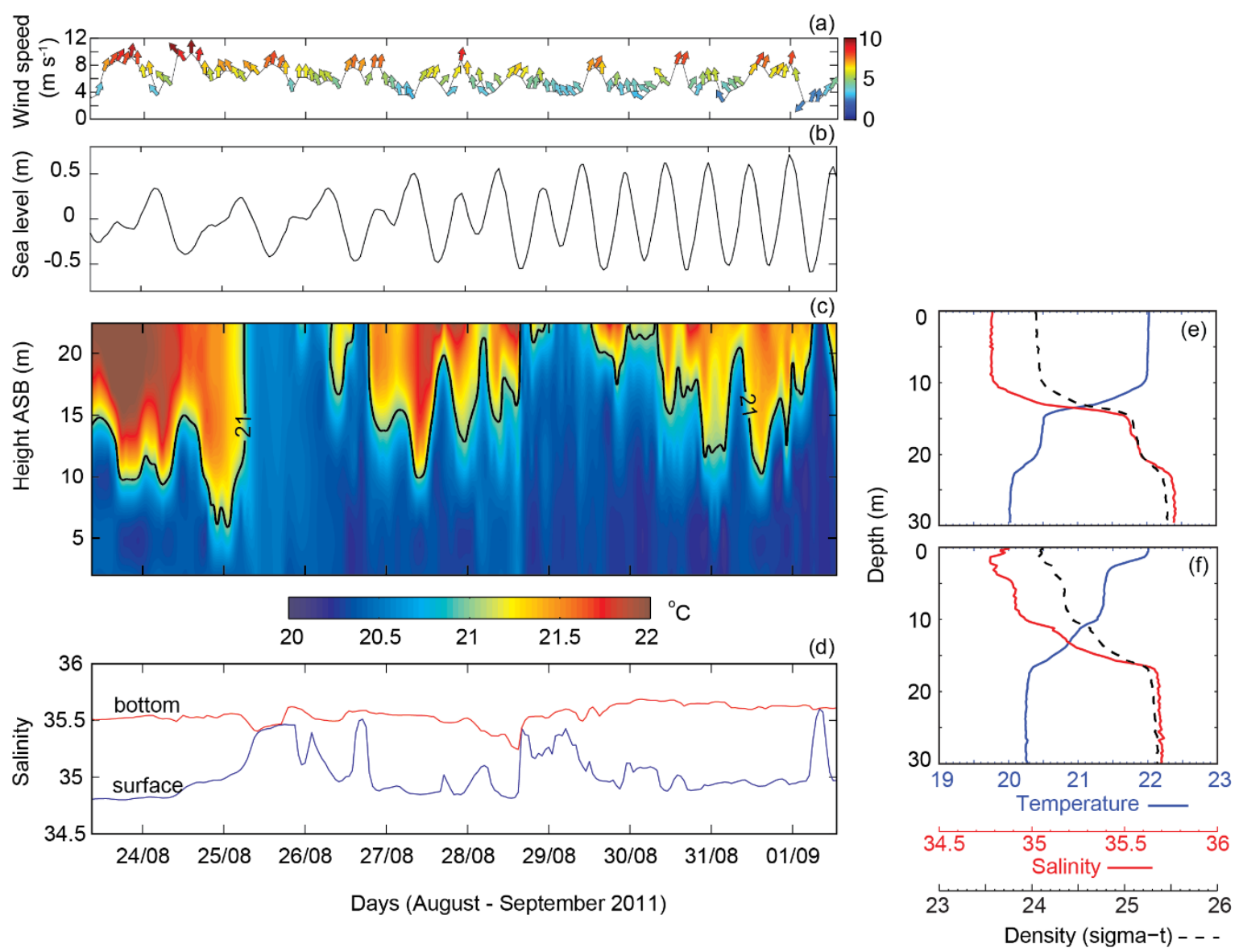

Figure 4. Time series of wind, sea level, temperature, and salinity at mooring M1 during August-September, 2011. (a) Carnarvon wind speed and direction "to" (arrows) with shading indicating speed in $\mathrm{m} \mathrm{s}^{-1}$; (b) Sea level from Carnarvon tide gauge (ADCP-Acoustic Doppler Current Profiler pressure sensor data contained errors due to tampering with mooring after 29 August 2011); (c) Temperature data from thermistor chain interpolated to $0.2 \mathrm{~m}$ bins in the vertical, referenced to height above sea bed (ASB), with $21^{\circ} \mathrm{C}$ contour marking the interface between surface (offshore) and bottom (Bay) waters. (d) Corresponding moored thermistor chain time series of surface and bottom salinity from $2 \mathrm{~m}$ above the seabed (red line) and $5 \mathrm{~m}$ below the surface (blue line). CTD profiles in centre of channel (C1 in Figure 1a) for (e) 23 August 2011 and (f) 1 September 2011. Some minor salinity spiking is evident near the surface.

The duration of vertically well-mixed periods ranged from 12-24 h on 25 and 29 August to 2-6 h on 26 and 28 August and 1 September (Figure 4c). Salinity destratification for these periods was typically shorter in duration, and not as complete, with only three events (25, 28 August and 1 September) of completely homogeneous conditions (Figure $4 \mathrm{~d}$ ). Salinity destratification occurred 
over a period of minutes (e.g., $\sim 2$ min on 1 September 2011) or hours (e.g., $\sim 3 \mathrm{~h}$ on 25 August), usually at the end of the ebb tide. The fact that the temperature/salinity destratification did not always coincide with particularly strong wind events (Figure $4 a, c$ ), or increased tidal forcing (Figure 4b,c), suggested that these events were due to the front crossing the mooring location. Concurrent remotely sensed SST images verified that the front had moved north of the mooring for at least one of these events (e.g., 25 August; Figure 3b). This longer duration event followed two days of stronger southerly winds (Figure 4a), which might explain the northward position of the front. The other events were too short in duration to be clearly visible in the daily satellite images; however, the cycle of destratification and restratification coincided with the ebb and flood of the tide, respectively (Figure $4 b, c)$. Another aspect of these short destratified periods was that the entire water column became cooler and more saline, as the denser bottom (or Bay) water extended over the entire water column.

\subsection{Currents}

In Geographe Channel, mean flow over the observation period was directed out of the Bay throughout the water column, with strongest mean velocity of $0.18 \mathrm{~m} \mathrm{~s}^{-1}$ occurring at a height of $8 \mathrm{~m}$ above the seabed (Figure 5d). The time series data confirmed that the outflow dominated over most of the water column, even during the flood tide (Figure $5 b-g$ ). The subsurface outflow weakened somewhat during the flood tide, but did not reverse in direction near the seabed until the end of the observations (Figure $5 \mathrm{f}-\mathrm{g}$ ), when tidal forcing increased. Under stronger tidal forcing conditions (26-29 August), two-layer flows developed during each flood tide, with surface inflow and bottom outflow (Figure $5 \mathrm{c}-\mathrm{g}$ ).
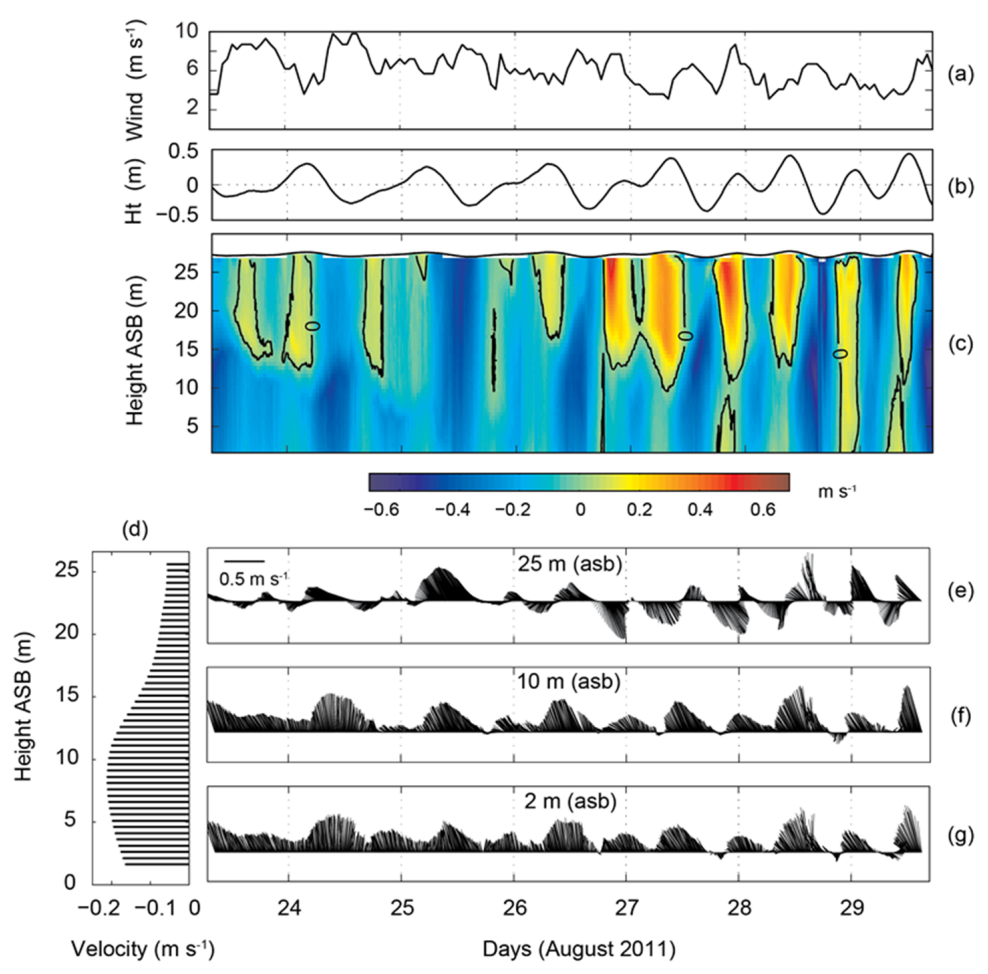

Figure 5. Observed wind, current velocity and sea level data from ADCP at mooring M1. (a) Wind speed from Carnarvon; (b) Water level derived from ADCP pressure sensor (m); (c) Along channel velocity. The zero velocity contour is shown with negative values (cool colours) representing flow out of the Bay and positive values (warm colours) representing flow into the Bay; (d) Mean along channel velocity profile for 6 days with negative values indicating flow out of the Bay (toward NNW); and, (e-g) Stick plots of velocities at $25 \mathrm{~m}, 10 \mathrm{~m}$, and $2 \mathrm{~m}$ above the seabed respectively. Vectors represent true direction (oceanographic convention) with the northward currents flowing out of the Bay. 
Maximum depth-mean velocities $\left(0.4-0.6 \mathrm{~m} \mathrm{~s}^{-1}\right)$ occurred during ebb tides when tidal flows combined with the residual, density-driven bottom outflow and strong southerly winds (Figure 5a-c). Tidal velocities increased toward the end of the experiment as the tides became more semidiurnal and the range increased slightly $(\sim 0.20 \mathrm{~m})$. Sharp changes in the velocity profile, visible as vertical striations in the ADCP time series, were observed on the 26 and 28 August around low tide (Figure 5c). These corresponded to rapid changes in stratification measured by the thermistor chain (Figure 4a), and can be attributed to the passage of the ocean front over the mooring. In particular, on 28 August at 15:15 WST, over 1-2 min, a sharp peak in velocity was followed by a shift of the outflow from the bottom to the surface.

Although the ADCP recorded data for only 6 of the 9 days, the data captured a broad range of conditions. The timespan of the observations was sufficient to describe the velocity structure over the transition from weak to strong tidal currents over the synodic cycle, and under varying wind (3-10 $\mathrm{m} \mathrm{s}^{-1}$ ) and vertical stratification conditions (Figure 5a-c).

\subsection{Turbulent Mixing and Dense Water Outflows (Geographe Channel 2011)}

Outflows persisted throughout the experiment, as noted previously, despite increasing tidal forcing and associated turbulent mixing. Velocities were low-pass filtered (38-h Butterworth filter) to remove the tides and reveal the residual outflow. The strongest sustained outflow $\left(\sim 0.25 \mathrm{~m} \mathrm{~s}^{-1}\right)$ occurred at the start of the experiment (Figure 6f), with two distinct surface and bottom layers, and a shear interface between them in the mid water column (Figure 6b-I). Estimates of turbulent kinetic energy (TKE) production (P) from the variance method (Equations (1) and (2)) allowed for a description of the timing and structure of the turbulent mixing related to the velocity profile (Figure $6 \mathrm{~b}$ ) enabling an assessment of the role of turbulent mixing in the modulation of the dense water outflow. Estimates of $\mathrm{P}$ ranged from as high as $\sim 0.03 \mathrm{~W} \mathrm{~m}^{-3}\left(-1.5 \log _{10}\left(\mathrm{~W} \mathrm{~m}^{-3}\right)\right.$ equivalent) to values below the threshold of detection for the ADCP data collected (masked in Figure 6b). Mean peak values of $P$ near the bottom throughout the 6-day deployment were in the order of $\sim 0.0015 \mathrm{~W} \mathrm{~m}^{-3}\left(-2.8 \log _{10}\left(\mathrm{~W} \mathrm{~m}^{-3}\right)\right.$ equivalent), with highest magnitudes near the seabed at times of strongest velocities, although there were some exceptions due to stratification effects. The height to which turbulence extended above the seabed both influenced, and was influenced by, the state of vertical stratification (Figure $6 \mathrm{~b}, \mathrm{e}$ ). When the water column was vertically stratified, high P occurred below and within the shear layer (Figure 6b-III), with the interface acting to block the bed-generated turbulence from reaching the surface waters (e.g., 23-25 August). Following a strong wind event on 24 August, the mixed layer deepened due to wind mixing at the surface (and movement of the front) (Figure 6b). On the following day, P generated at the seabed extended to within $5 \mathrm{~m}$ of the surface, meeting the surface turbulence, with outflow over all depths and homogeneous temperature and salinity (Figure 6e-f). The variability is summarised below in the three regimes of TKE production that were identified from the field data (Figure 6):

1. The highest rate of $\mathrm{P}$ was consistently found near the seabed, with $\mathrm{P}$ not symmetric between flood and ebb. The flood rate of $\mathrm{P}\left(\sim 10^{-4} \mathrm{~W} \mathrm{~m}^{-3}\right)$ was typically $<20 \%$ of the rate during max ebb flow $\left(\sim 10^{-3} \mathrm{~W} \mathrm{~m}^{-3}\right)$ (Figure 6b-I).

2. Strongest pulses in $\mathrm{P}\left(\sim 10^{-2} \mathrm{~W} \mathrm{~m}^{-3}\right)$ occurred near the seabed during times of maximum shear but with low current speeds. This occurred during flood tides, despite low flow speeds when strong tidal forcing opposed the near-bed outflow under stratified conditions (e.g., 26, 28 August; Figure 6b-II).

3. A region of increased rates of $\mathrm{P}\left(\sim 10^{-3} \mathrm{~W} \mathrm{~m}^{-3}\right)$ existed in the shear layer interface in the mid water column (Figure 6b-III). During times of low tidal flows, this interface had rates of $\mathrm{P}>3$ times those near the seabed at corresponding times. 
Overall, $\mathrm{P}$ was closely related to the speed of the current, with $\left|\mathrm{U}_{\mathrm{b}}{ }^{3}\right|$ providing a qualitative representation of $\mathrm{P}$ (Figure 6c). However, $\left|\mathrm{U}_{\mathrm{b}}{ }^{3}\right|$ failed to represent the turbulence generated near the bottom during flood tide, when stronger tidal inflows opposed outflows, with high P but low currents speeds. The turbulence associated with shear at the density interface was another feature that was not evident in the time series of current speed $\left(\left|\mathrm{U}_{\mathrm{b}}{ }^{3}\right|\right.$, Figure $\left.6 \mathrm{c}\right)$. Turbulence estimates near the surface have been shown to be unreliable, due to wave contamination and beam spreading during all but the calmest conditions (e.g., [35]). To be conservative, estimates of TKE production near the surface (often high) were ignored for this analysis. However, high P near the surface can still be used to qualitatively describe wind-generated turbulence.

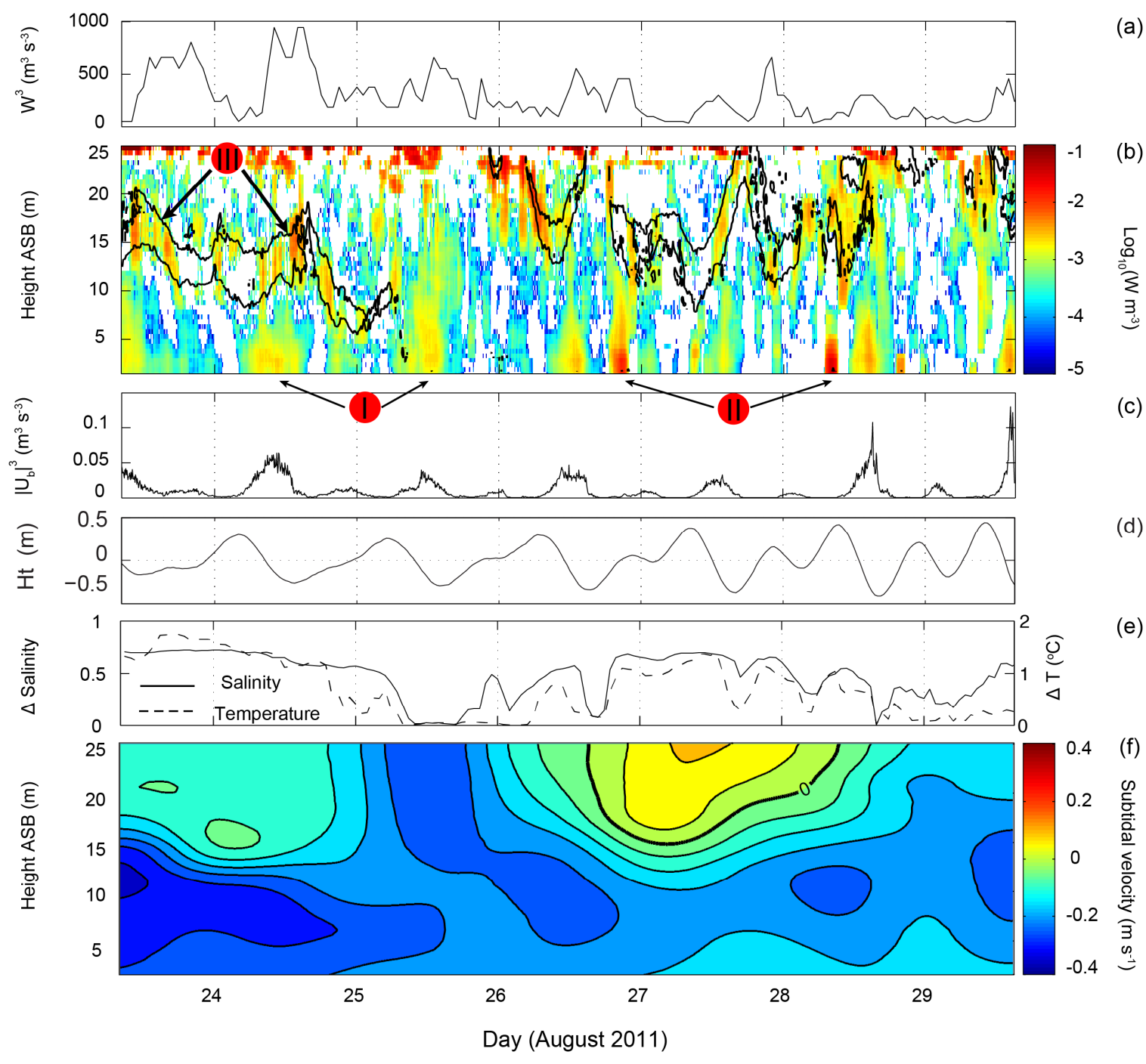

Figure 6. ADCP mooring data (M1) from Geographe Channel for August 2011. (a) Wind speed cubed from Carnarvon weather station as proxy for wind mixing; (b) Turbulent kinetic energy production (P) estimated using the variance method overlaid with the $0.002 \mathrm{~s}^{-2}$ shear-squared contour. Units are in $\log _{10}\left(\mathrm{~W} \mathrm{~m}^{-3}\right)$ to be consistent with published literature. White areas represent $\mathrm{P}$ values below the instrument noise confidence threshold; (c) Cube of bottom current speed $\left(\left|\mathrm{U}_{\mathrm{b}}{ }^{3}\right|\right) \sim 2 \mathrm{~m}$ above the seabed as proxy for tidal mixing; (d) Sea level (e) Temperature and salinity difference between surface and bottom; (f) Principal axis lowpass ( $38 \mathrm{~h}$ ) filtered current velocity (to remove the tide) with negative values (blue) representing flow out of the Bay, to the NNW. Warmer colours indicate flow into the Bay; the zero velocity contour is shown by a thicker black line. 


\subsection{Turbulent Mixing and Dense Water Outflows (Naturaliste Channel 2009)}

For comparison between entrance channels, data from the first experiment in Naturaliste Channel [17] were re-analysed to include estimates of TKE production, as was done with the Geographe Channel data. During the 28-day period, three outflow events occurred: around 30 June, 7 July and 19 July 2009, coinciding with weak winds (Figure 7d), minimal tidal currents (Figure 7g), and low turbulent kinetic energy production (Figure $7 \mathrm{f}$ ). To enable a more detailed comparison between the two data sets, an equivalent subset of the Naturaliste Channel data was selected to represent the transition from equatorial to tropic tides (Figure 7a-c). During this period the increase in tidal forcing caused the transition from weak to strong current speeds (up to $\sim 0.6 \mathrm{~m} \mathrm{~s}^{-1}$ ), with increased turbulence causing the shutdown of the dense water outflow from Naturaliste Channel. The highest rates of $\mathrm{P}\left(\sim 6 \times 10^{-3} \mathrm{~W} \mathrm{~m}^{-3}\right)$ were found near the seabed, with levels decreasing linearly towards the higher bins, where they dropped below the detection threshold. Although higher winds around 20 July (Figure 7d) might have contributed to the mixing, this analysis focuses on the bed-generated turbulence due to the low confidence in estimates of $P$ near the surface. Qualitatively however, the influence of the wind can be seen in the elevated values of $P$ on 20 July in the upper portion of the water column (Figure $7 \mathrm{~b}$ ) coinciding with high wind speed (Figure $7 \mathrm{~d}$ ). A clear relationship existed between $\left|\mathrm{U}_{\mathrm{b}}{ }^{3}\right|$ and $P$ over the period, with higher estimates of $P$ related to higher current speeds. Rates of TKE production were similar between flood and ebb, in contrast to Geographe Channel, where there was a strong asymmetry. Turbulence levels at the start of the subset observation period ( 16-19 July) were low and masked by instrument noise, and therefore, indicated as white space in Figure $7 \mathrm{~b}$. The vertical structure of P for Naturaliste Channel was less complex than for the Geographe Channel data, with insufficient shear between surface and bottom flows to generate $\mathrm{P}$ above the detection threshold in the mid-water column over the entire 28-day period. This can be attributed to the fact that the maximum subtidal bottom outflow velocity was only $~ 30 \%$ of the outflow observed in Geographe Channel.

Variability in TKE production over the tropic-equatorial cycle highlighted the positive relationship between high rates of $\mathrm{P}$, high current speeds, and minimum stratification (Figure $7 \mathrm{f}-\mathrm{h}$ ). The mixed period from 1-4 July (Figure $7 \mathrm{~h}$ ) can be explained by mixing from strong winds. Some minor asymmetry in $\mathrm{P}$ between flood and ebb occurred due to the varying tidal gradient rather than the effects of the outflow on the flooding tide, as was seen in the Geographe Channel data. Again, maximum stratification and the occurrence of dense water outflows in Naturaliste Channel ( 30 June, 7 July, 19 July) coincided with the lowest levels of $\mathrm{P}$ (ranging from below the threshold of detection to $2 \times 10^{-3} \mathrm{~W} \mathrm{~m}^{-3}$ ) and minimum current speeds. 

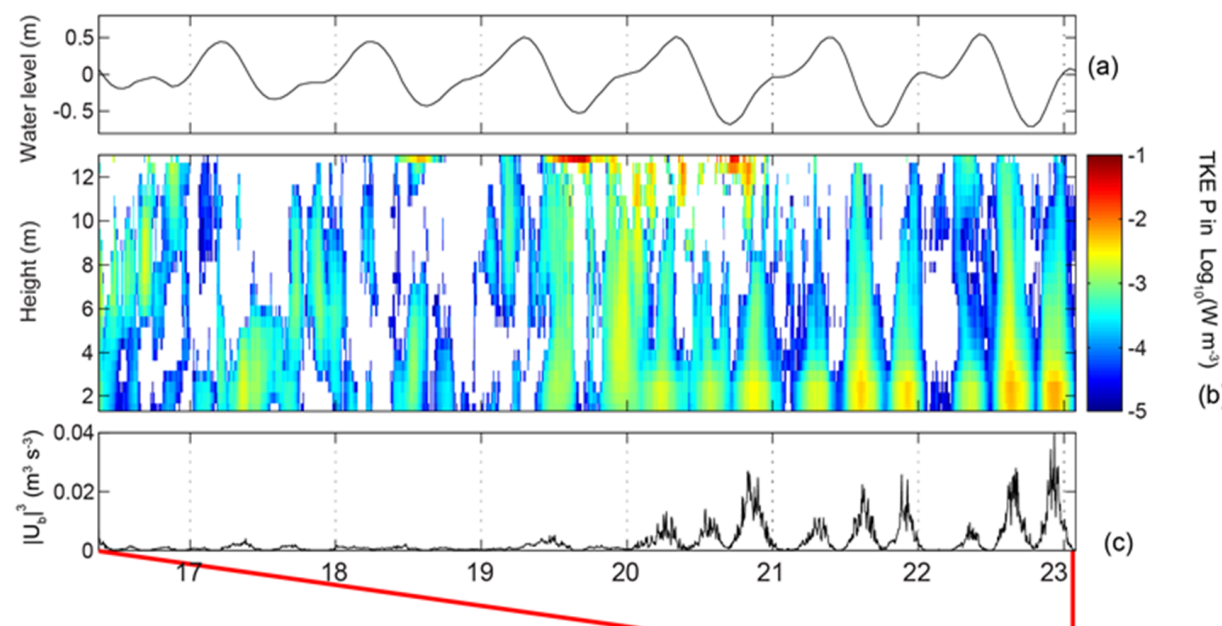

(c)

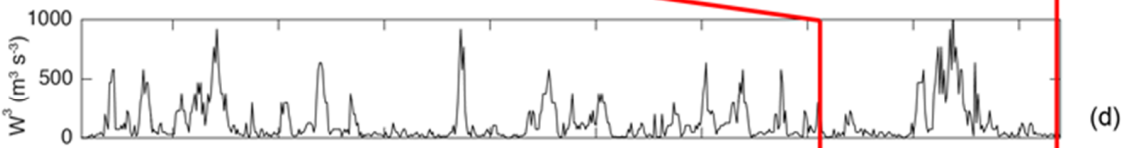

(d)

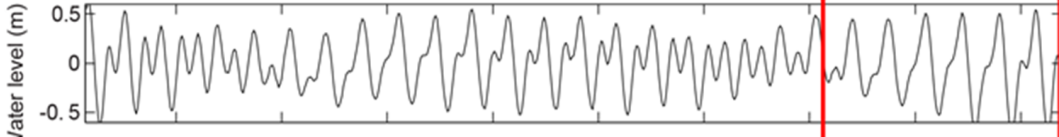

(e)
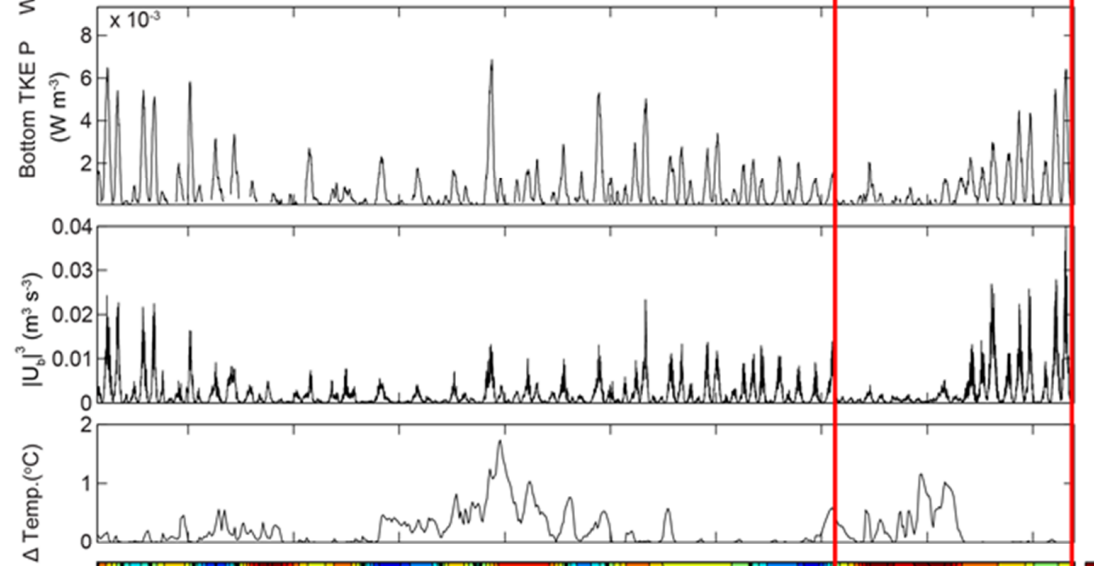

(f)

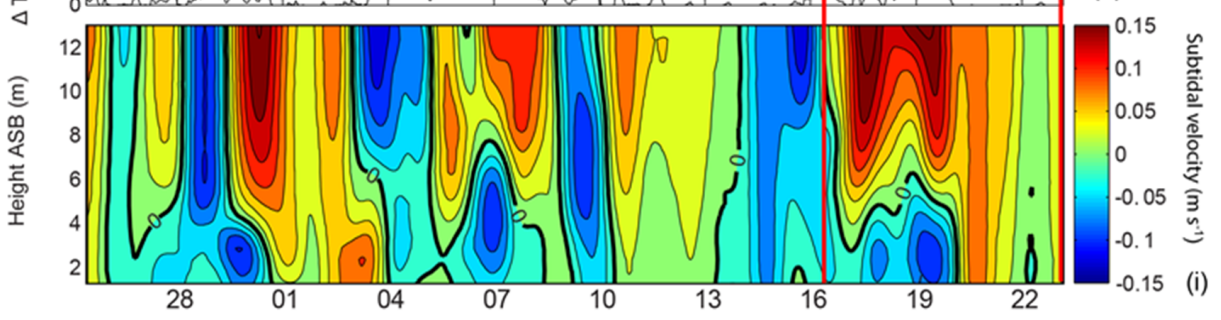

Day (June/July 2009)

Figure 7. ADCP mooring data (M2) from Naturaliste Channel for June/July 2009 with a-c showing a temporal subset (16-23 July 2009) to highlight a similar period to Figure 6. (a) Water level derived from ADCP pressure sensor; (b) Turbulent kinetic energy production $(\mathrm{P})$ in $\log _{10}\left(\mathrm{~W} \mathrm{~m}^{-3}\right)$. The shear-squared contour is omitted due to the absence of a shear layer. White indicates $\mathrm{P}$ below noise threshold; (c) Bottom current speed cubed $\left(\left|\mathrm{U}_{\mathrm{b}}{ }^{3}\right|\right) \sim 2 \mathrm{~m}$ above the seabed as proxy for tidal mixing; (d) Wind speed cubed as proxy for wind mixing; (e) Water level; (f) $\mathrm{P}$ in $\log _{10}\left(\mathrm{~W} \mathrm{~m}^{-3}\right) \sim 2 \mathrm{~m}$ above the seabed; (g) Bottom current speed cubed $\left(\left|\mathrm{U}_{\mathrm{b}}{ }^{3}\right|\right) \sim 2 \mathrm{~m}$ above the seabed; (h) Temperature difference (surface-bottom); (i) Principal axis lowpass (38 h) filtered current velocity with negative values (cool colours) representing flow out of the Bay, to the WSW and positive (warm colours) showing flow into the Bay. 


\section{Discussion}

Persistent density-driven bottom outflows caused by longitudinal temperature and salinity gradients were measured in August 2011 out of Geographe Channel, the northern entrance to Shark Bay. The mean flow was directed offshore for the entire water column, with the main mean flow $\left(\sim 0.2 \mathrm{~m} \mathrm{~s}^{-1}\right)$ approximately $8 \mathrm{~m}$ above the seabed. This was $2-3$ times stronger than the intermittent outflow measured in June/July 2009 in Naturaliste Channel [17]. The velocity and stratification data presented here provide the first quantitative evidence of a dominant outflow through Shark Bay's northern Geographe Channel, and is one of few global examples of persistent outflow from a hypersaline bay. The outflow was first proposed by James et al. [14], based on sediment and hydrographic samples offshore, and has been simulated in numerical models [19,41]. Woo et al. [15] also measured a higher salinity signature near the northern entrance, as compared to the western entrance, but the outflow was never recorded directly.

Stratification during the 2011 Geographe Channel experiment was modified by the tidal cycle, mostly through the movement of the front over the mooring site. However, tidal mixing and wind mixing appeared to be insufficient to mix the water column completely, despite consistent $\sim 3-10 \mathrm{~m} \mathrm{~s}^{-1}$ southerly winds and increasing tidal current speeds.

Because vertical mixing acts against stratification and the formation of density-driven bottom currents $[18,42]$, finding a reliable proxy that allows for the prediction of when outflows are likely to occur is particularly useful. The cube of the tidal current speed, $\left|\mathrm{U}_{\mathrm{b}}{ }^{3}\right|$, is proportional to available turbulent mixing energy, and is commonly used [42]. However, the ability to estimate Reynolds stresses and turbulent kinetic energy production (P) from ADCP data allows for a more detailed examination of the turbulent transport processes involved. Estimates of $\mathrm{P}$ in Naturaliste Channel closely followed the pattern of $\left|\mathrm{U}_{\mathrm{b}}{ }^{3}\right|$, with generation of turbulence from the seabed through tidal friction, decreasing with height away from the bed, during both flood and ebb. The estimates for Geographe Channel showed a more complex structure. In general, highest rates of P coincided with maximum current speeds. However, it was not symmetrical between flood and ebb, as current speeds during flood were reduced due to the outflow along the bottom opposing the flood tide. The result of the stratification was turbulence generation in the shear layer in mid water column, and several periods of maximum rates of turbulent mixing near the bottom when the flood tide opposed the outflow, with very low resultant current speeds. The dense water outflow in Geographe Channel was only somewhat dampened by the stronger currents associated with the tropic tides, whilst in Naturaliste Channel, stratification disappeared during tropic tides. Despite the differences between the two entrance channels, $\left|\mathrm{U}_{\mathrm{b}}{ }^{3}\right|$ on average appeared to be sufficient to predict when outflows were likely to occur, or strengthen, over the tropic-equatorial cycle for both entrances to Shark Bay.

The most obvious explanation for stronger northward flow out of Geographe Channel is the orientation and size/depth of the channels in relation to the longitudinal density gradients. Geographe Channel is orientated normal to the main axis of the longitudinal density gradient, whilst Naturaliste Channel is parallel. This orientation favoured a higher flow out of the northern channel, as it provided a more direct pathway. Additionally, Geographe Channel in the north is both wider $(40 \mathrm{~km}$ vs. $30 \mathrm{~km}$ ) and deeper ( 28 m vs. $18 \mathrm{~m}$ ), compared to Naturaliste Channel in the west (Figure 1). The deeper Geographe Channel would favour stratification, thereby encouraging the enhanced outflow. For periods of high (southerly) winds, when much of the Bay becomes vertically mixed, the outflow is likely dominated by barotropic wind-driven forces [19]. Separating the baroclinic and barotropic components is difficult, but the persistence of vertical stratification and bottom outflow in Geographe Channel, regardless of tidal stage and winds, suggests that the barotropic flows are superimposed on the underlying density-driven flows described above.

Measured subtidal outflow velocities for Geographe Channel were $\sim 0.2 \mathrm{~m} \mathrm{~s}^{-1}$, and for Naturaliste Channel $\sim 0.1 \mathrm{~m} \mathrm{~s}^{-1}$, with higher water depths suggesting a larger volume of water could flow out of the north. Taking into consideration measured flow velocities and coinciding cross-sectional areas of $1.3 \times 106 \mathrm{~m}^{2}$ and $4.1 \times 105 \mathrm{~m}^{2}$ for Geographe and Naturaliste Channels respectively, rough estimates of 
volume flux through the channels yield $2.6 \times 10^{5} \mathrm{~m}^{3} \mathrm{~s}^{-1}$ for Geographe Channel and $4.1 \times 10^{4} \mathrm{~m}^{3} \mathrm{~s}^{-1}$ for Naturaliste Channel. This suggests that the volume flux out of the northern entrance is a factor of 10 greater than for the western entrance, and thus, that the flow out of Geographe Channel is important for maintaining the salinity gradients that support the unique ecosystem across Shark Bay.

The main south-to-north channel along the Eastern Gulf that connects Geographe Channel to the hypersaline waters of Hamelin Pool (salinity 65) is also deeper and wider than Denham Sound that connects Naturaliste Channel to the less hypersaline waters of Henry Freycinet Harbour (salinity 250) (Figure 1). This would also enhance stratification and formation of dense bottom currents in the east and north-central regions of the Bay, in comparison to the western region (Denham Sound). In an earlier hydrographic survey of the Bay [12], strong stratification was found to the east of Cape Peron (Figure 1), but mixed waters to the west. Modeling studies by Nahas et al. [13] also supported this explanation. These authors used the Simpson-Hunter parameter [43] to estimate the location between stratified and mixed waters within the Bay. The predictions, confirmed by the present study in Geographe Channel, revealed that the northern section of the Bay would be stratified, whilst the gulfs would be mixed. The orientation and parallel alignment of the main axis of the longitudinal density gradient along the deeper, straighter, more stratified channel would encourage the denser waters from the Eastern Gulf to exit northwards out of Geographe Channel. Whilst the main volume of outflow may exit through Geographe Channel, Naturaliste Channel could still act as the main connection to the ocean for Denham Sound in the western half of Shark Bay.

Dense water outflows have been recorded in similar inverse estuarine systems such as Spencer Gulf in Australia [4,6], Hervey Bay, Australia [7], and the Upper Gulf of California, Mexico [9]. The modulation of the outflow due to tidal mixing in these environments was usually more pronounced than what was measured in the present study. However, Shark Bay experiences a much smaller tidal range, with the difference between tropic and equatorial tidal ranges $(\sim 0.3-0.5 \mathrm{~m})$ an order of magnitude smaller than the spring/neap variance in Spencer Gulf and the Gulf of California [44]. The steady outflow through Geographe Channel is presumably related to the smaller tidal variability and relative strength of the longitudinal density gradients. Another important distinction is Shark Bay's more complex geography and multiple entrance channels, as compared to the more open bays mentioned above.

Potential biological influences of the dense water outflows in Shark Bay include the larval dispersal of commercially fished scallops and prawns that have experienced high interannual variability. The main trawling grounds for these species are aligned south-north, in-line with channel bathymetry and main bottom current pathways. Previous dispersal modeling studies indicated that outflows near the seabed could flush particles representing larvae out of the Bay, or create a virtual hydrodynamic barrier between some areas, whilst the northward mean flow through the centre of the Bay connected other fishing grounds [45]. The observations presented here indicating strong outflow through the northern channel, therefore, provide further evidence that dense bottom currents are likely an important mechanism driving larval dispersal and hydrodynamic flushing, as has been proposed previously [45-47].

\section{Conclusions}

Observations of a steady, near-bed dense water outflow from Shark Bay's Geographe Channel support earlier hypotheses that the main export of water from the Bay occurs out of the Geographe Channel (in the north). The measured dense water outflow was 2-3 times stronger than the outflows recorded previously in Naturaliste Channel (in the west), and was more resistant to breakdown by tidal mixing.

Estimates of turbulence production for both channels showed the main source of turbulence to be tidal flow over the seabed, with the cube of the bottom current speed, $\left|\mathrm{U}_{b}{ }^{3}\right|$, providing a reasonable proxy for tidal mixing and prediction of dense water outflows from Shark Bay most of the time. However, persistent vertical stratification in Geographe Channel, and shear between surface and 
bottom layers, caused high levels of turbulence production throughout the water column, and altered the temporal variability. Unlike Naturaliste Channel, the highest levels of turbulence production were observed when tidal flows reversed direction, and were higher on the flood tide when the dense water outflow opposed tidal currents. The orientation and bathymetry of Geographe Channel along the main axis of the longitudinal density gradient provides one explanation for the stronger outflow from the Bay's northern entrance.

These density-driven currents are not only important for maintaining the salt budget of the hypersaline Bay, but are likely important drivers of dispersal of suspended matter throughout Shark Bay. The outflows likely influence recruitment of commercially fished scallops, prawns, and snapper, through dispersal and flushing of larvae.

Author Contributions: Y.H., C.P., and H.M. designed the field experiments; Y.H. and H.M. performed the experiments; Y.H. analyzed the data; H.M. contributed analysis tools; Y.H. prepared the manuscript with input from all co-authors and C.P. provided input and review on all aspects of the study.

Acknowledgments: The fieldwork was funded by a Fisheries Research and Development (FRDC) grant and Y.H. was supported by The University of Western Australia through an International Postgraduate Research Scholarship. H.M. was supported through the Group of Eight (Go8) European Fellowship during his residence at The University of Western Australia. The authors gratefully acknowledge Johanna Rosman and Philip Wiles for assistance with turbulence calculations using the ADCPs and for providing the MATLAB code.

Conflicts of Interest: The authors declare no conflicts of interest.

\section{References}

1. Pritchard, D.W. Estuarine Hydrography. In Advances in Geophysics; Landsberg, H.E., Ed.; Elsevier: Amsterdam, The Netherlands, 1952; pp. 243-280.

2. Shearman, R.K.; Brink, K.H. Evaporative dense water formation and cross-shelf exchange over the northwest Australian inner shelf. J. Geophys. Res. 2010, 115, C06027. [CrossRef]

3. Pattiaratchi, C.; Hollings, B.; Woo, M.; Welhena, T. Dense shelf water formation along the south-west Australian inner shelf. Geophys. Res. Lett. 2011, 38, L10609. [CrossRef]

4. Lennon, G.W.; Bowers, D.G.; Nunes, R.A.; Scott, B.D.; Ali, M.; Boyle, J.; Cai, W.J; Herzfeld, M.; Johansson, G.; Nield, S.; et al. Gravity Currents and the Release of Salt from an Inverse Estuary. Nature 1987, 327, 695-697. [CrossRef]

5. Nunes, R.; Lennon, G. Physical property distributions and seasonal trends in Spencer Gulf, South Australia: An inverse estuary. Mar. Freshw. Res. 1986, 37, 39-53. [CrossRef]

6. Nunes, R.A.; Lennon, G.W. Episodic Stratification and Gravity Currents in a Marine-Environment of Modulated Turbulence. J. Geophys. Res.-Oceans 1987, 92, 5465-5480. [CrossRef]

7. Ribbe, J. A study into the export of saline water from Hervey Bay, Australia. Estuarine. Coast. Shelf Sci. 2006, 66, 550-558. [CrossRef]

8. Largier, J.L.; Hollibaugh, J.T.; Smith, S.V. Seasonally Hypersaline Estuaries in Mediterranean-climate Regions. Estuarine. Coast. Shelf Sci. 1997, 45, 789-797. [CrossRef]

9. Lavin, M.F.; Godinez, V.M.; Alvarez, L.G. Inverse-estuarine features of the Upper Gulf of California. Estuar. Coast. Shelf Sci. 1998, 47, 769-795. [CrossRef]

10. Valle-Levinson, A.; Delgado, J.A.; Atkinson, L.P. Reversing Water Exchange Patterns at the Entrance to a Semiarid Coastal Lagoon. Estuar. Coast. Shelf Sci. 2001, 53, 825-838. [CrossRef]

11. Ivanov, V.V.; Shapiro, G.I.; Huthnance, J.M.; Aleynik, D.L.; Golovin, P.N. Cascades of dense water around the world ocean. Prog. Oceanogr. 2004, 60, 47-98. [CrossRef]

12. Burling, M.C.; Ivey, G.N.; Pattiaratchi, C.B. Convectively driven exchange in a shallow coastal embayment. Cont. Shelf Res. 1999, 19, 1599-1616. [CrossRef]

13. Nahas, E.L.; Pattiaratchi, C.B.; Ivey, G.N. Processes controlling the position of frontal systems in Shark Bay, Western Australia. Estuar. Coast. Shelf Sci. 2005, 65, 463-474. [CrossRef]

14. James, N.P.; Collins, L.B.; Bone, Y.; Hallock, P. Subtropical carbonates in a temperate realm: Modern sediments on the southwest Australian shelf. J. Sediment. Res. 1999, 69, 1297-1321. [CrossRef]

15. Woo, M.; Pattiaratchi, C.; Schroeder, W. Summer surface circulation along the Gascoyne continental shelf, Western Australia. Cont. Shelf Res. 2006, 26, 132-152. [CrossRef] 
16. Logan, B.W.; Cebulski, D.E. Sedimentary Environments of Shark Bay, Western Australia; American Association of Petroleum Geologists: Tulsa, OK, USA, 1970; pp. 1-37.

17. Hetzel, Y.; Pattiaratchi, C.; Lowe, R. Intermittent dense water outflows under variable tidal forcing in Shark Bay, Western Australia. Cont. Shelf Res. 2013, 66, 36-48. [CrossRef]

18. Linden, P.F.; Simpson, J.E. Modulated mixing and frontogenesis in shallow seas and estuaries. Cont. Shelf Res. 1988, 8, 1107-1127. [CrossRef]

19. Hetzel, Y.; Pattiaratchi, C.; Lowe, R.; Hofmeister, R. Wind and tidal mixing controls on stratification and dense water outflows in a large hypersaline bay. J. Geophys. Res. Oceans 2015, 120, 6034-6056. [CrossRef]

20. Burling, M.C.; Pattiaratchi, C.B.; Ivey, G.N. The tidal regime of Shark Bay, Western Australia. Estuar. Coast. Shelf Sci. 2003, 57, 725-735. [CrossRef]

21. DASETT. Nomination of Shark Bay, Western Australia by the Government of Australia for Inclusion in the World Heritage List; The Department of the Arts, Sport, the Environment: Tourism, Territories, 1990.

22. Smith, R.L.; Huyer, A.; Godfrey, J.S.; Church, J.A. The Leeuwin Current off Western Australia, $1986-1987$. J. Phys. Oceanogr. 1991, 21, 323-345. [CrossRef]

23. Pattiaratchi, C.B.; Woo, M. The mean state of the Leeuwin Current system between North West Cape and Cape Leeuwin. J. R. Soc. West. Aust. 2009, 92, 221-241.

24. Pattiaratchi, C.; Hegge, B.; Gould, J.; Eliot, I. Impact of sea-breeze activity on nearshore and foreshore processes in southwestern Australia. Cont. Shelf Res. 1997, 17, 1539-1560. [CrossRef]

25. Chao, Y.; Li, Z.J.; Farrara, J.D.; Hung, P. Blending Sea Surface Temperatures from Multiple Satellites and In Situ Observations for Coastal Oceans. J. Atmos. Ocean. Technol. 2009, 26, 1415-1426. [CrossRef]

26. Lumpkin, R.; Pazos, M. Measuring surface currents with Surface Velocity Program drifters: The instrument, its data, and some recent results. In Lagrangian Analysis and Prediction of Coastal and Ocean Dynamics; Cambridge University Press: Cambridge, UK, 2007; pp. 39-67.

27. Emery, W.J.; Thomson, R.E. Data Analysis Methods in Physical Oceanography; Pergamon Press: Oxford, UK, $1997 ; 634 p$.

28. Beardsley, R.C.; Limeburner, R.; Rosenfeld, L.K. CODE-2: Moored Array and Large-Scale Data Report; WHOI-85-35; Woods Hole Oceanographic Institution: Woods Hole, MA, USA, 1985; 234p.

29. Lohrmann, A.; Hackett, B.; Roed, L.P. High-resolution measurements of turbulence, velocity and stress using a pulse-to-pulse coherent sonar. J. Atmos. Ocean. Technol. 1990, 7, 19-37. [CrossRef]

30. Stacey, M.T.; Monismith, S.G.; Burau, J.R. Observations of turbulence in a partially stratified estuary. J. Phys. Oceanogr. 1999, 29, 1950-1970. [CrossRef]

31. Lu, Y.; Lueck, R.; Huang, D. Turbulence Characteristics in a Tidal Channel. J. Phys. Oceanogr. 2000, 30, 855-867. [CrossRef]

32. Rippeth, T.; Williams, E.; Simpson, J. Reynolds Stress and Turbulent Energy Production in a Tidal Channel. J. Phys. Oceanogr. 2002, 32, 1242-1251. [CrossRef]

33. Stacey, M.T.; Monismith, S.G.; Burau, J.R. Measurements of Reynolds stress profiles in unstratified tidal flow. J. Geophys. Res. 1999, 104, 10933-10949. [CrossRef]

34. Baumert, H.Z.; Simpson, J.; Sündermann, J. Marine Turbulence: Theories, Observations, and Models; Cambridge University Press: Cambridge, UK, 2005.

35. Rippeth, T.P.; Simpson, J.H.; Williams, E.; Inall, M.E. Measurement of the Rates of Production and Dissipation of Turbulent Kinetic Energy in an Energetic Tidal Flow: Red Wharf Bay Revisited. J. Phys. Oceanogr. 2003, 33, 1889. [CrossRef]

36. Lu, Y.; Lueck, R.G. Using a Broadband ADCP in a Tidal Channel. Part II: Turbulence. J. Atmos. Ocean. Technol. 1999, 16, 1568-1579. [CrossRef]

37. Williams, E.; Simpson, J.H. Uncertainties in estimates of Reynolds stress and TKE production rate using the ADCP variance method. J. Atmos. Ocean. Technol. 2004, 21, 347-357. [CrossRef]

38. Nidzieko, N.J.; Fong, D.A.; Hench, J.L. Comparison of Reynolds stress estimates derived from standard and fast-ping ADCPs. J. Atmos. Ocean. Technol. 2006, 23, 854-861. [CrossRef]

39. Souza, A.; Howarth, M. Estimates of Reynolds stress in a highly energetic shelf sea. Ocean Dyn. 2005, 55, 490-498. [CrossRef]

40. Rosman, J.H.; Hench, J.L.; Koseff, J.R.; Monismith, S.G. Extracting Reynolds stresses from acoustic Doppler current profiler measurements in wave-dominated environments. J. Atmos. Ocean. Technol. 2008, 25, $286-306$. [CrossRef] 
41. Burling, M.C. Oceanographic Aspects of Shark Bay, Western Australia, in School of Environmental Systems Engineering; University of Western Australia: Perth, Australia, 1998; p. 101.

42. Nunes Vaz, R.A.; Lennon, G.W.; Samarasinghe, J.R.D. The Negative Role of Turbulence in Estuarine Mass Transport. Estuar. Coast. Shelf Sci. 1989, 28, 361-377. [CrossRef]

43. Simpson, J.H.; Hunter, J.R. Fronts in Irish Sea. Nature 1974, 250, 404-406. [CrossRef]

44. Lavin, P.M.F.; Marinone, M.S.G.L. An overview of the physical oceanography of the Gulf of California. In Nonlinear Processes in Geophysical Fluid Dynamics; Velasco Fuentes, O.U., Sheinbaum, J., Ochoa de la Torre, J.L., Eds.; Kluwer Academic Publishers: Dordrecht, The Netherlands, 2003.

45. Kangas, M.I.; Chandrapavan, A.; Hetzel, Y.L.; Sporrer, E.C. Minimising Gear Conflict and Resource Sharing Issues in the Shark Bay Trawl Fisheries and Promotion of Scallop Recruitment; Fisheries Research Report No. 229; Department of Fisheries: Western Australia, Australia, 2012; 136p.

46. Joll, L.M.; Caputi, N. Environmental influences on recruitment in the saucer scallop (Amusium balloti) fishery of Shark Bay, Western Australia. ICES Mar. Sci. Symp. 1995, 199, 47-53.

47. Caputi, N.; Fletcher, W.J.; Pearce, A.; Chubb, C.F. Effect of the Leeuwin Current on the recruitment of fish and invertebrates along the Western Australian coast. Mar. Freshw. Res. 1996, 47, 147-155. [CrossRef]

(C) 2018 by the authors. Licensee MDPI, Basel, Switzerland. This article is an open access article distributed under the terms and conditions of the Creative Commons Attribution (CC BY) license (http:// creativecommons.org/licenses/by/4.0/). 